\title{
The effects of dietary fat content on the growth and body composition of lean and genetically obese Zucker rats adrenalectomized before weaning
}

\author{
BY J. M. FLETCHER* AND N. MCKENZIE \\ Rowett Research Institute, Bucksburn, Aberdeen AB2 9SB
}

(Received 3 February 1988 - Accepted 5 June 1988)

\begin{abstract}
1. Lean $(\mathrm{Fa} /-)$ and obese $(\mathrm{fa} / \mathrm{fa})$ Zucker rats were adrenalectomized or sham-operated at $18 \mathrm{~d}$ of age $(3 \mathrm{~d}$ before weaning). After weaning the rats were fed ad lib. on semi-synthetic diets containing either a low $(8 \mathrm{~g} / \mathrm{kg})$ or a high $(178 \mathrm{~g} / \mathrm{kg})$ proportion of fat. Other groups of sham-operated rats were given the same amount eaten by adrenalectomized animals (restricted intake). Rats were killed at $40 \mathrm{~d}$ of age.

2. Adrenalectomy reduced the body lipid content of lean and obese rats compared with intact animals fed ad lib. or given a restricted intake. Adrenalectomized obese rats contained more body lipid than intact or adrenalectomized lean rats.

3. Sham-operated obese rats given a restricted intake had less body protein than similarly treated lean animals and this phenotypic difference was abolished by adrenalectomy.

4. There were no effects of diet on growth or body composition of intact or adrenalectomized rats.

5. It is concluded that preweaning adrenalectomy prevented development of the obese phenotype when rats were fed on either diet. Comparison of these results with a previous study, in which adrenalectomized Zucker rats were fed on a stock diet (Fletcher, 1986 b), showed, however, that feeding either of the semi-synthetic diets caused greater deposition of body lipid in obese rats.
\end{abstract}

The underlying defect responsible for development of genetic obesity in the rat $(f a / f a)$ or mouse $(o b / o b)$ is not understood. The abnormal body composition, hyperphagia, hyperinsulinaemia and insulin resistance of the obese rat and mouse can, however, be prevented by adrenalectomy (Yukimura et al. 1978; Saito \& Bray, 1984; Fletcher, 1986a). The effects of adrenalectomy are thought to be a consequence of glucocorticoid deprivation as treatment of adrenalectomized obese animals with natural or synthetic glucocorticoids restored the obese phenotype (Saito \& Bray, 1984; Freedman et al. 1986; Fletcher, $1986 a$ ).

After weaning, laboratory rats are customarily fed on a diet containing a high proportion of carbohydrate and the excessive adipose tissue deposition shown by obese rats is largely due to de novo lipogenesis (Haggarty et al. 1987). Glucocorticoids are important factors in the control of lipogenesis in normal animals. For example, intact rats refed on a highcarbohydrate diet after a period of starvation increase their rate of hepatic lipogenesis several-fold compared with normally fed animals (Kaul \& Berdanier, 1975; Berdanier et al. 1976). Adrenalectomized rats are unable to make this adaptation and glucocorticoid replacement restores this capacity (Bouillon \& Berdanier, 1980). It is therefore possible that adrenalectomy prevents development of obesity in Zucker rats by inhibition of lipogenesis from dietary carbohydrate. If this hypothesis is correct, adrenalectomized obese rats would still be able to accumulate excess adipose tissue from diets containing a high proportion of dietary fat. It has been reported that giving a diet containing a high proportion of fat to adrenalectomized obese mice allowed development of the obese phenotype (Smith \& Romsos, 1985).

In the present study the effects of preweaning adrenalectomy on the growth and body compositon of lean $(\mathrm{Fa} /-)$ and obese $(f a / f a)$ Zucker rats have been investigated when rats

* Present address: Unilever Research, Colworth Laboratory, Sharnbrook, Bedford MK44 1LQ. 
Table 1. Composition of low- and high-fat diets $(\mathrm{g} / \mathrm{kg})$

\begin{tabular}{lcc}
\hline & Low-fat & High-fat \\
\hline Casein & 200 & 223 \\
Flour & 287 & 322 \\
Sucrose & 432 & 76 \\
Maize oil & 8 & 178 \\
Vitamin and mineral mix & 73 & 83 \\
Cellulose & 0 & 118 \\
\hline
\end{tabular}

* As described by Miller \& Bender (1955).

were fed on semi-purified diets containing either a low or a high proportion of fat from weaning to $40 \mathrm{~d}$ of age. Because adrenalectomy is associated with a reduced food intake of both lean and obese rats, the effects of these diets have also been investigated in intact rats fed to the intake of adrenalectomized animals.

MATERIALS AND METHODS

Lean $(\mathrm{Fa} / \mathrm{-})$ and obese $(\mathrm{fa} / \mathrm{fa})$ Zucker rats were bred from heterozygote parents from a colony at the Rowett Research Institute. Phenotype identification was made at $18 \mathrm{~d}$ of age on the basis of the lower rectal temperature of obese animals (Godbole et al. 1978) as described previously (Fletcher 1986a). After weaning, rats were housed singly at $22^{\circ}$. Because there were no significant differences in body composition between male and female rats at $40 \mathrm{~d}$ of age, both sexes have been used in the present study. Each experimental group, however, consisted of an equal number of male and female rats. The food intakes of adrenalectomized animals were measured every 2-3 d and intact pair-fed lean and obese rats were provided daily with their appropriate diet and amount of food. The composition of the diets are given in Table 1 .

Bilateral adrenalectomies or sham operations were performed under diethyl ether anaesthesia using a single dorsal incision at $18 \mathrm{~d}$ of age. After weaning at $21 \mathrm{~d}$, adrenalectomized rats were given drinking water containing sodium chloride $(9 \mathrm{~g} / \mathrm{l})$ and glucose $(40 \mathrm{~g} / 1)$. Sham-operated rats received water containing glucose $(40 \mathrm{~g} / \mathrm{l})$ only. To ensure survival of adrenalectomized obese rats, at weaning all rats were injected with 50 $\mu \mathrm{g}$ Dexamethasone (Sigma Chemical Co., Poole, Dorset) in $0.1 \mathrm{ml}$ sesame oil (Fletcher, $1986 a$ ). Adrenalectomized rats having plasma corticosterone concentrations greater than $20 \mu \mathrm{g} / 1$, or evidence of surviving adrenal fragments post-mortem, were excluded from these studies.

Rats were killed and blood samples taken between 09.00 and 10.00 hours at $40 \mathrm{~d}$ of age. Stomachs were removed and the remaining carcases freeze-dried, minced and analysed for total lipid by the method of Atkinson et al. (1972) and nitrogen by the Kjeldahl method (crude protein was calculated at $\mathrm{N} \times 6.25$ ). Ash was determined as the residue after combustion.

Plasma glucose was analysed by the glucose oxidase (EC 1.1.3.4) method (Hugget \& Nixon, 1957). Plasma insulin and corticosterone were measured by radioimmunoassay. Iodinated insulin and tritiated corticosterone were purchased from Amersham International Plc, Bucks. Insulin and corticosterone anti-sera were purchased from Miles Scientific Plc, Stoke Poges, Slough. Rat insulin standard (lot 615-063-12-3) was obtained from Eli Lilley and corticosterone standard was purchased from Sigma Chemical Co. 
Diet and genetic obesity after adrenalectomy

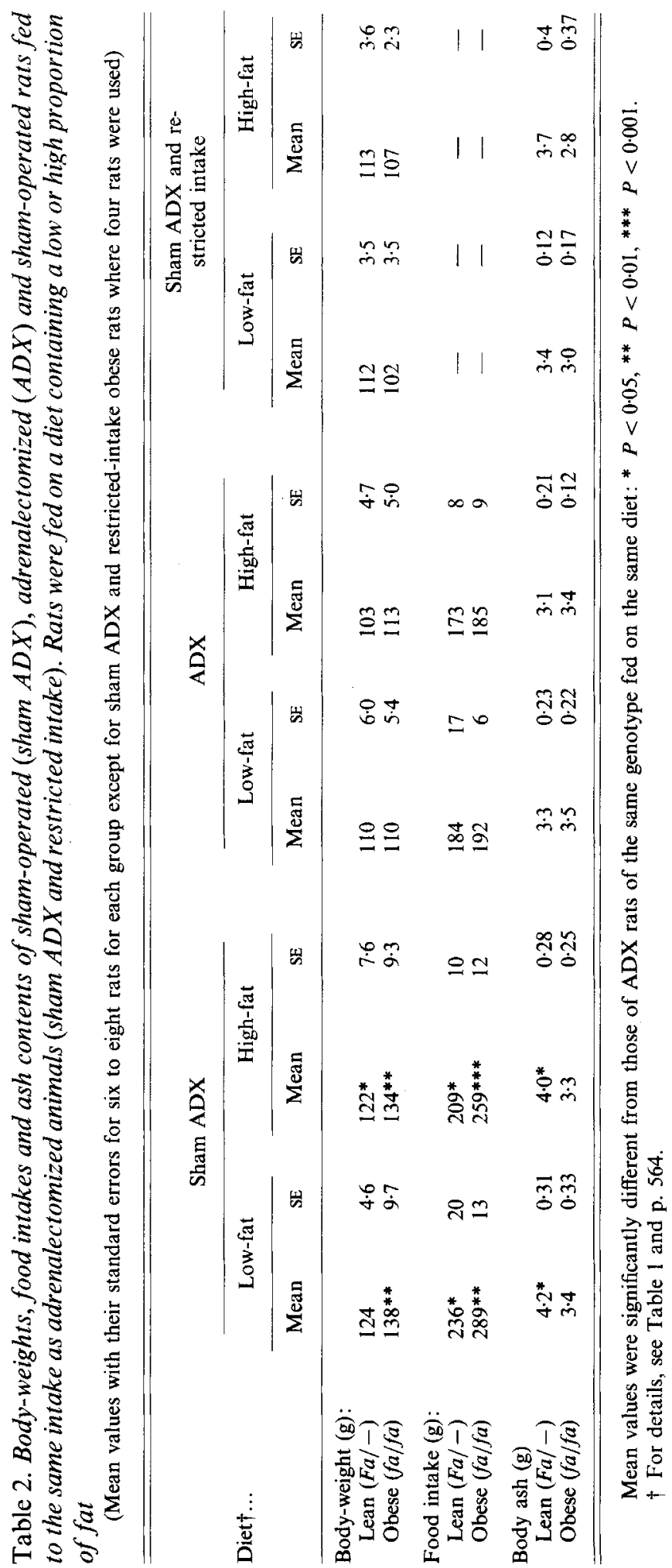


屡

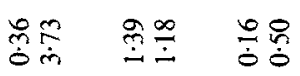

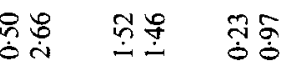


Results were analysed by a $2 \times 2 \times 3$ factorial design analysis of variance and the significances of differences between mean values were established by Student's $t$ test. Mean values with their standard errors are given.

\section{RESULTS}

Intact obese rats ate more than lean animals when fed on either diet (Table 2). Adrenalectomy reduced the intake of both obese and lean rats and prevented the hyperphagia of obese animals.

Tables 2 and 3 show that adrenalectomy reduced body lipid and ash contents of lean rats, and also body-weight in lean rats fed on the high-fat diet.

Adrenalectomy reduced the body-weight and lipid content of obese rats but had no significant effect on body protein and ash contents (Tables 2 and 3). Intact obese rats, pairfed to the intake of adrenalectomized animals, had more lipid $(P<0.01)$, less protein $(P<0 \cdot 01)$ and less ash $(P<0 \cdot 1)$ than adrenalectomized obese rats.

Despite the reduction in lipid content of obese rats caused by adrenalectomy, they still contained more lipid than adrenalectomized lean rats $(P<0.001)$. Body protein and ash contents did not significantly differ between lean and obese rats after adrenalectomy. There were no effects of dietary type on body-weight or composition in either phenotype after adrenalectomy or when intact rats were fed to the intake of adrenalectomized animals.

Plasma insulin concentrations were higher in intact obese rats than in intact lean animals when fed on either diet $(P<0.001)$ and adrenalectomy abolished this hyperinsulinaemia (Table 3). There were no significant differences in glycaemia between obese and lean rats or between diets (values not shown).

\section{DISCUSSION}

Adrenalectomy was effective in abolishing the hyperphagia and hyperinsulinaemia of obese rats. Although adrenalectomized obese rats still contained more lipid than adrenalectomized or intact lean rats, they only accumulated approximately one-third of the lipid content of intact obese animals. These effects on the growth and insulinaemia of obese rats were not simply a consequence of reduced food intake, as shown by comparison with the effects of pair-feeding on intact obese rats. In particular, the body protein content of adrenalectomized obese rats was greater than that of pair-fed intact obese rats. The ability of intact obese rats preferentially to deposit lipid at the expense of body protein, when expression of their hyperphagia is prevented, has been well documented (Bray et al. 1973; Cleary et al. 1980) and increased secretion of glucocorticoids may be instrumental in achieving this abnormal pattern of growth (Fletcher, 1986c).

There was no effect of dietary type on growth or body composition of intact or adrenalectomized obese rats. It is unlikely, therefore, that a reduced capacity for de novo lipogenesis in adrenalectomized rats is responsible for their reduced fatness. In contrast, Smith \& Romsos (1985) reported that giving a semi-synthetic diet containing a high proportion of fat to adrenalectomized obese mice restored their body lipid content to that of intact obese mice, and restored all other features of the intact obese phenotype. These conflicting results may represent a fundamental difference between the obese mouse and rat; alternatively they may be attributed to the amount of dietary fat or type of fat. In the study of Smith \& Romsos (1985) the high-fat diet contained $320 \mathrm{~g}$ fat $/ \mathrm{kg}$ compared with $178 \mathrm{~g} / \mathrm{kg}$ in the present study. Whereas beef tallow was a component of the fat in the diet of Smith \& Romsos (1985), only maize oil was used in the present study. Tallow and maize oil differ in fatty acid composition and probably in other minor components. In particular, 
tallow, being derived from animal adipose tissue, may contain dissolved steroid hormones (Zomzely et al. 1959) and only small amounts of exogenous glucocorticoids are required to restore the complete obese phenotype in adrenalectomized obese animals (Saito \& Bray, 1984; Freedman et al. 1986; Fletcher, 1986b).

Although giving a high- or low-fat semi-synthetic diet did not restore the obese phenotype, comparison of the present findings with those of a previous study carried out in this laboratory (Fletcher $1986 \mathrm{~b}$ ) does reveal an effect of diet on the ability of adrenalectomized obese rats to deposit body lipid. Lean and obese rats were adrenalectomized and maintained under identical conditions to those described here, except that rats were fed on a commercially available pelleted stock diet from weaning (Fletcher, 1986b). At $40 \mathrm{~d}$ of age the body lipid contents of adrenalectomized lean and obese rats were 3.6 (SE 0.3 ) g and 6.4 (SE 0.8 ) g respectively (Fletcher, $1986 b$ ). The value for the obese but not the lean rats fed on stock diet was signifiantly lower $(P<0 \cdot 001)$ than that found in the present study for adrenalectomized obese rats fed on either low- or high-fat semi-synthetic diets. The stock diet used in the previous study (Fletcher, 1986 ) had a fat content of $24 \mathrm{~g} / \mathrm{kg}$ and the fat contents of the semi-synthetic diets used in the present study were chosen so as to provide values above and below that of the stock diet, 8 and $178 \mathrm{~g} / \mathrm{kg}$ in the low- and high-fat diets respectively. The differential ability of stock and semi-synthetic diets to ameliorate the effects of adrenalectomy on the body lipid content of obese rats, is, therefore, not related to dietary fat content. An alternative explanation may lie in the semi-synthetic diets having a greater palatability compared with stock diet, leading to a larger energy intake.

Intact obese rats retain dietary energy more efficiently than lean animals (Pullar \& Webster, 1974) and adrenalectomy has been reported to abolish this phenotypic difference (Marchington et al. 1983). In the present study adrenalectomized obese rats did not consume signficantly more food than adrenalectomized lean animals and had the same lean body mass, but they did, however, deposit more body lipid. Studies with stock-fed adrenalectomized obese rats (see above) have shown that only a small proportion of this excess lipid deposition may be attributable to the degree of obesity present before adrenalectomy and the effects of glucocorticoid replacement at weaning (Fletcher, 1986 b). Rats were also given drinking water containing glucose, and water intakes were not measured. The amount of glucose consumed was, however, likely to have been small, and water intake is very closely related to solid food intake. The magnitude of the difference in lipid content between adrenalectomized lean and obese rats therefore suggests that obese rats were still energetically more efficient than lean animals.

Intact lean rats, fed to the same intake as adrenalectomized animals, had the same lean body mass but also accumulated more body lipid than adrenalectomized rats. This finding suggests a greater energetic efficiency in intact than in adrenalectomized lean rats, although the reservations regarding access to drinking water containing glucose, noted previously, are also applicable. Further studies are clearly required to ascertain the energetic efficiency of adrenalectomized lean and obese rats fed on semi-synthetic diets.

The expert statistical assistance of Mrs Hazel Vint is gratefully acknowledged. Rat insulin standard was a generous gift from Eli Lilley plc.

\section{REFERENCES}

Atkinson, T., Fowler, V. R., Garton, G. A. \& Lough, A. K. (1972). Analyst 97, 562-568.

Berdanier, C. D., Wurdeman, R. \& Tobin, R. D. (1976). Journal of Nutrition 106, 1791-1800.

Bouillon, D. \& Berdanier, C. D. (1980). Journal of Nutrition 110, $286-297$.

Bray, G. A., York, D. A. \& Sverdloff, R. S. (1973). Metabolism 22, $435-444$.

Cleary, M. P., Vasselli, J. R. \& Greenwood, M. R. C. (1980). American Journal of Physiology 284, E284 E292. 
Fletcher, J. M. (1986a). British Journal of Nutrition 56, 141-151.

Fletcher, J. M. (1986 b). Biochemical Journal 238, 459-463.

Fletcher, J. M. (1986c). Physiology and Behaviour 37, 597-602.

Freedman, M. R., Horwitz, B. A. \& Stern, J. S. (1986). American Journal of Physiology 250, R595-R607.

Godbole, V., York, D. A. \& Bloxham, D. B. (1978). Diabetologia 15, 41-44.

Haggarty, P., Wahle, K. W. J., Reeds, P. J. \& Fletcher, J. M. (1987). International Journal of Obesity 11 , $41-50$.

Huggett, A. St \& Nixon, D. A. (1957). Lancet ii, 368-370.

Kaul, L. \& Berdanier, C. D. (1975). Journal of Nutrition 105, 1176-1185.

Marchington, D., Rothwell, N. J., Stock, M. J. \& York, D. A. (1983). Journal of Nutrition 113, $1395-1402$.

Miller, D. S. \& Bender, A. E. (1955). British Journal of Nutrition 9, 382-388.

Pullar, J. D. \& Webster, A. J. F. (1974). British Journal of Nutrition 31, 377-392.

Saito, M. \& Bray, G. A. (1984). American Journal of Physiology 246, R20-R25.

Smith, C. K. \& Romsos, D. R. (1985). American Journal of Physiology 249, R13-R22.

Yukimura, Y., Bray, G. A. \& Wolfson, A. R. (1978). Endocrinology 103, 1924-1928.

Zomzely, C. R., Asti, R. \& Mayer, J. (1959). Science 129, 1546-1547. 